\title{
Pensando Criativamente na Universidade
}

\author{
Solange Muglia Wechsler \\ Pontificia Universidade Católica de Campinas
}

Uma das maiores queixas entre os professores universitários das mais diferentes áreas de conhecimento, sejam eles da graduação ou pós-graduação, é a dificuldade dos alunos de pensarem criativamente. Esta observação, aliás corretamente feita pelos professores, faz sentido se pensarmos que o aluno universitário vem de todo um sistema de ensino onde a repetição e a memorização são as únicas formas de pensar valorizadas, ou seja, as únicas estratégias que lhes permitem obter maiores notas ou melhores avaliações pelos seus professores. Não é de se admirar ,portanto, que os alunos tenham dificuldades de pensar criativamente ao chegarem à universidade.

Esta deficiência é sentida no ensino da graduação e tornar-se crítica, ou altamente prejudicial, durante o curso de pós-graduação "strictu" ou "latu sensu", onde é esperado que o aluno vá além dos textos e produza hipóteses de pesquisa a serem testadas em forma de dissertações e teses, gerando, assim, novos conhecimentos sobre um determinado problema..

As habilidades para se escrever uma monografia, projeto de pesquisa, dissertação ou uma tese são várias, mas, infelizmente, muitas vezes, elas são compreendidas como sendo, exclusivamente, o resultado de um processo de aprender a fazer busca bibliográfica. Embora esta seja, ao nosso ver, uma habilidade essencial para se fundamentar o pensamento à medida que verifica 0 que já foi conseguido por diversos especialistas sobre o tema, até o momento, ela não se sustenta por si só, em uma proposta de trabalho. O resultado de se acreditar nesta única habilidade é a observação que podemos fazer de trabalhos onde pareça existir uma colcha de retalhos, ou idéias desconcertadas, onde se verifica uma longa séria de citações, segundo este autor e segundo aquele autor, levando à apresentação de um texto monótono, enfadonho, pouco estimulante à curiosidade do leitor, e, conseqüentemente, sem que haja propostas novas e criativas sobre o tema delimitado.

Como fazer com que os estudantes universitários se tornem escritores mais criativos? De que maneiras romper as barreiras do pensamento repetitivo e memorizado que estes alunos trazem de suas experiências anteriores educacionais? Sem dúvidas, para isso é necessário que eles sejam também leitores mais criativos. Somente aqueles que lêem questionando as informações e procurando novas idéias a partir de uma informação dada poderão ser capazes de colocar no papel os seus pensamentos e propostas de uma forma mais divergente, ou seja, se transformam em escritores criativos.

Uma das primeiras idéias errôneas a ser trabalhada com o estudante universitário é que os textos técnicos ou de pesquisa não constituem verdade absoluta e podem ser questionados. Deve ser mostrado que toda nova teoria ou descoberta científica foi derivada ou colocada em prática por aqueles que ousaram questionar e buscar outras possibilidades ou formas de explicação. Observamos, entre os nossos estudantes, um certo medo da palavra escrita como se pelo fato de um texto estar impresso conferisse o seu "status" de veracidade, no julgamento daqueles que permitiram que ele estivesse em tal veículo de informação, seja em um livro, revista científica ou até mesmo em um jornal de divulgação.

Temos, portanto, a pergunta: Como ajudar o aluno a ter coragem de questionar? É possível eliminar este medo desenvolvendo mais confiança? É neste sentido que apresentamos a seguir uma 
estratégia que temos utilizado com sucesso no nosso ensino de graduação e pós-graduação a fim de facilitar o aparecimento de leitores e escritores mais criativos.

Definimos como habilidades básicas para a leitura criativa três estratégias básicas: 1) Questionar as informações dadas; 2) Buscar diferentes explicações para os fatos apresentados; 3) Traçar possíveis implicações ou conseqüências do que foi apresentado. A partir das aplicações destas estratégias, o aluno estará pronto a escrever não somente um, mas vários textos sob um mesmo tema, utilizando diferentes pontos de vista.

Os passos a serem seguidos pelos professores universitários interessados em desenvolver habilidades do pensamento criativo nos seus alunos são os seguintes:

\section{Escolha do texto}

Comece escolhendo um texto que não esteja diretamente ligado com a sua área de ensino. Por exemplo, se você está ensinando Psicologia, não inicie por um livro ou revista desta área, para poder eliminar um pouco do medo de questionar algo já publicado por um psicólogo. Somente depois de ter trabalhado este primeiro texto é que você pode, pouco a pouco, introduzir textos de Psicologia e pedir o mesmo tipo de pensamento criativo.

Procure um texto de uma revista ou jornal de grande circulação, com um título sugestivo e de preferência que não seja muito longo, aproximadamente uma página. Tire cópias para os alunos do texto, mas não entregue para começar, somente no meio do exercício como explicaremos.

Escolhemos, para exemplificar esta estratégia, um texto da revista VEJA, de 6 de maio de 1998, página 93, com o seguinte título e subtítulo:

\section{A segunda onda: Depois de mexer no ensino fundamental, o governo prepara uma grande reforma no segundo grau.}

\section{2) Questionando o título:}

A primeira etapa desta estratégia é trabalhar somente com o título. Escreva o título na lousa para dar mais possibilidades de exploração. Não entregue a cópia do artigo agora.

A sua função como professor é encorajar perguntas sobre este título. O que eles gostariam de saber em um artigo sobre este tema? O que deveria estar escrito neste artigo?

Encoraje a fluência de idéias, almejando chegar a 30 ou 40 perguntas sobre o texto. Explore não somente as palavras do título e subtítulo, mas também o que poderia estar por trás delas ou os seus diferentes significados. Vá escrevendo na lousa as idéias dos alunos, porque uma idéia pode dar carona a uma nova sugestão, levando a um fenômeno grupal de criatividade.

Trabalhe sempre com os princípios da "tempestade de idéias", ou seja, quanto mais idéias, melhores as chances de aparecerem boas idéias. Não emita julgamentos de certo ou errado, nem bom ou mau, ou possível ou impossível, lembre-se de que a crítica é assassina de idéias.

Permita e facilite o aparecimento do humor nas idéias. O humor, geralmente, traz idéias novas e originais.

Calcule cerca de dez a quinze minutos para esta primeira parte. Você verá quantas idéias boas podem aparecer neste pouco espaço de tempo

Exemplificaremos abaixo com umas 30 possíveis sugestões para o questionamento deste título e subtítulo: 
1. Qual foi a primeira onda?

2. Por que uma onda?

3. Que vai acontecer com a segunda onda?

4. Por que se mexeu no ensino fundamental?

5. É necessária uma grande reforma?

6. Quem foi consultado sobre esta reforma?

7. Vai melhorar o ensino com esta reforma?

8. Alguém ficou satisfeito com esta reforma?

9. Como esta reforma afeta o sistema de ensino público e particular?

10. Por que só agora foi feita uma reforma?

11. Quem pressionou o governo para fazer esta reforma?

12. A terceira onda vai ser para a universidade?

13. Quanto tempo vai durar a segunda onda?

14. Esta onda vai morrer na praia ou vai ser praticada?

15. A reforma no segundo grau é conserto ou inovação?

16. Quem está envolvido na preparação desta reforma?

17. Foi avaliado o ensino fundamental depois de mexido?

18. Será esta uma forma de se buscarem votos para a reeleição?

19. Qual vai ser o efeito desta reforma no salário dos professores?

20. Como ficará o lazer dos alunos do segundo grau, vai melhorar ou piorar?

21. Como será feita a avaliação desta reforma no segundo grau?

22. Se não der certo a reforma, voltaremos ao estágio inicial?

23. De que país importamos desta vez a idéia da reforma?

24. Os professores receberão treinamento especial para esta segunda onda?

25. Que apoio foi dado aos professores ao se mexer no ensino fundamental?

26. Como foi afetada a vida dos alunos após as mudanças no ensino fundamental?

27. Como os pais dos alunos avaliam as mexidas no ensino fundamental?

28. Quantas ondas serão necessárias para melhorar a educação no Brasil?

29. As ondas são só propostas teóricas ou envolvem investimento na educação?

30. A onda vai chegar a todos os lugares do Brasil, mesmo onde não haja ou exista mar?

\section{2) Buscando diversas causas ou explicações}

Dê, para cada aluno ou para cada par de alunos, uma cópia do texto e peça-lhe(s) para buscarem quais das perguntas que fizeram foi respondida no texto ou quais não foram respondidas. Esta é uma maneira de ir além da informação dada, lendo textos de forma crítica e questionada.

Continue questionando com os alunos. A informação dada é suficiente? Onde poderíamos achar mais dados sobre este assunto? O que mais ler ou procurar? Desta maneira, você está evitando que o aluno seja um simples consumidor da informação, o que tende a ser reforçado pela televisão e se tome, cada vez mais, um leitor curioso e criativo.

A fim de continuar a exemplificação da estratégia, reproduziremos abaixo uma parte do texto citado:

Após várias novidades para melhorar o ensino fundamental, o governo está preparando uma grande 
reforma para o ensino do segundo grau. As mudanças que serão aprovadas no Conselho Nacional de Educação em junho devem entrar em vigor já no ano que vem. O principal objetivo é devolver ao ensino médio o caráter de curso de formação geral. Criado na década de 60, o segundo grau brasileiro é um modelo de ensino ultrapassado, que já não cumpre as suas funções. Ele não fornece conhecimentos técnicos necessários para quem pretenda ingressar imediatamente no mercado de trabalho nem prepara de forma adequada aos alunos que desejem seguir adiante e fazer um curso superior. Em dez anos, o número de formados no segundo grau dobrou, foi de 1,2 milhões de pessoas no ano passado. Ao mesmo tempo, registrou-se um alarmante desinteresse pelas faculdades. $O$ Instituto Nacional de Estudo se Pesquisa Educacionais fez um levantamento com 429775 jovens que terminaram o segundo grau no ano passado e descobriu que apenas 31,5\% deles pretendiam fazer o curso superior. Hoje, somente $11 \%$ dos brasileiros entre 18 a 24 anos fazem faculdade. Esse índice é de 35\% na Argentina, 40\% na França e 60\% nos Estados Unidos. "Isto mostra a urgência de redefinir o ensino médio, diz o ministro da Educação Paulo Renato de Souza.

Procure, agora, com seus alunos, quais perguntas foram respondidas totalmente, parcialmente, ou não foram respondidas no texto. Leia o texto todo, de maneira crítica, com os seus alunos. Ajude-os a se tomarem leitores curiosos e críticos e não consumidores da informação. Estimule a sua curiosidade e vontade de saber.

No nosso exemplo, podemos verificar o seguinte:

Perguntas respondidas plenamente:

$5,14,16$.

Perguntas respondidas parcialmente:

1,3, 7, 15, 23, 30.

Perguntas não respondidas:

2, 4, 6, 8, 9, 10, 11, 12, 13, 17, 18, 19, 20, 21, 22, 24, 25, 26, 27, 28, 29.

\section{3) Adivinhando conseqüências e implicações}

Nesta parte final do exercício, procure ir além da informação dada. Estimule o pensamento do pesquisador criativo. Encoraje o aparecimento de hipóteses. Dê espaço para a fantasia.

Peça aos alunos para sugerirem outras fontes de informação para preencherem as lacunas deste texto. Realmente o que querem saber já foi escrito ou documentado, ou ainda é um texto oculto, propositalmente ou não.

Estimule-os a buscarem os lados positivos e negativos de qualquer informação. Se estes fatos descritos se tornarem verdadeiros, o que poderá acontecer? Quais serão as possíveis conseqüências? Ajude os alunos a olharem para uma informação sob diferentes pontos de vista.

Novamente busque a fluência de idéias, trinta ou quarenta perguntas para facilitar o aparecimento de idéias diferentes. Registre as idéias na lousa para permitir que possam ver o que já foi pensado e proporem novas idéias. O humor será sempre bem-vindo, em todos os estágios deste exercício.

Trabalhando com o nosso exemplo, vamos pensar em possíveis conseqüências e implicações:

1. A educação brasileira vai melhorar

2. O desemprego vai acabar

3. As universidades vão ter suas vagas lotadas 
4. Novas universidades deverão ser construídas

5. Os estudantes de segundo grau vão ter uma ampla cultura geral

6. As universidades vão querer entrar na terceira onda

7. A segunda onda vai morrer na praia, porque não conseguirá ser implantada

8. Os professores do segundo grau não aceitarão a segunda onda por não estarem preparados

9. As editoras de livros didáticos do segundo grau vão faturar muito com novos livros

10. A avaliação da segunda onda pelos estudantes não vai ser positiva

11. O impacto da segunda onda no mercado de trabalho não mostrará o sucesso esperado

12. Uma segunda onda reformulada deverá ser pensada

13. Os pais dos estudantes do segundo grau ficarão estimulados e voltarão a estudar

14. A primeira onda não combinará com a segunda onda

15. A proposta das ondas vai acabar depois do período das eleições

16. A segunda onda será tão grande que se tornará uma enchente desestruturando a escola

17. A segunda onda só será implantada nas escolas particulares por causa do custo

18. Os pais dos alunos pedirão a volta do ensino tradicional para seus filhos

19. Shakespeare e Camões serão lidos novamente nas escolas públicas

20. A segunda onda não durará, porque não haverá investimento substancial na educação

21. O Congresso não aprovará a segunda onda para o ensino público

22. Diferentes países do mundo pedirão a cópia da nossa segunda onda

23. Várias nações remeterão as propostas de suas ondas para serem copiadas aqui.

23. Os especialistas do MEC não vão conseguir avaliar a segunda onda nos próximos dez anos

24. As avaliações da primeira e segunda onda levarão ao fechamento de muitas escolas

25. Os "surfistas" vão continuar quebrando as ondas para não irem à escola

26. Cursos de salva-vidas para a educação serão oferecidos em massa para os professores

27. O turismo nas praias vai ser estimulado com as propostas de tantas ondas

28. Novas escolas vão ser criadas à beira-mar para combinar com as ondas da educação

29. A literatura e a poesia ficarão bastante desenvolvidas com a segunda onda

30. A pós-graduação sentirá o efeito das mudanças com a quarta onda.

Estas são algumas das inúmeras sugestões que um texto como este pode apresentar. Não se preocupe com o certo ou o errado, o possível ou o impossível. Pense junto com os alunos nas inúmeras propostas de pesquisa que poderão ser geradas a partir de idéias como estas.

\section{4) Aplicando a estratégia a textos didáticos}

Peça aos alunos para escolherem um texto didático ou de pesquisa relacionado ao tema de sua próxima aula ou ofereça-lhes alguns textos possíveis para escolha.

Como tarefa de casa, a ser discutido em sala de aula, solicite o uso do mesmo tipo de raciocínio crítico-criativo, da seguinte maneira:

a) Escrever uma grande quantidade de perguntas (mínimo de 30 a 40) utilizando somente o título e o subtítulo (se houver) do texto escolhido, antes da leitura do mesmo.

b) Localizar, no texto, após a sua leitura, quais perguntas foram respondidas totalmente, parcialmente ou não foram respondidas no mesmo, assinalando os números das perguntas na lista anteriormente feita. 
c) Escrever todas as possíveis conseqüências e implicações que a leitura do texto possibilita, imaginando aspectos positivos e negativos da mesma., focalizando diferentes pontos de vista.

d) Propor diferentes tipos de pesquisa (bibliográfica, empírica, etc) que poderiam ser feitos para responder aos temas gerados neste exercício.

Em sala, peças aos alunos para lerem suas idéias, a fim de gerar uma discussão criativa em grupo sobre o texto. Devido ao tempo na sala de aula, solicite aos alunos que façam um revisão crítica do seu texto, assinalando as suas cinco melhores perguntas (etapa 1), as cinco maiores falhas no texto (etapa 2), as cinco conseqüências de que mais gostou (etapa 3), juntamente com as cinco propostas de pesquisa que mais lhe interessariam realizar sobre o tema. A partir deste exercício, o professor poderá pedir aos alunos que escolham uma pesquisa dentre as suas propostas para ser realizada sobre o tema e ser apresentada, futuramente, em sala de aula.

Concluindo, esta estratégia é bastante rica e permite o aparecimento de um grande número de idéias criativas. A sua aplicação pode ser realizada em qualquer nível de ensino universitário, passando da graduação até a pós-graduação O objetivo final é preparar, cada vez mais, o estudante universitário para ser um pensador independente, criativo e crítico diante da informação que o cerca., no sentido de poder identificar e solucionar novos problemas e não se tomar um mero repetido r dos conhecimentos adquiridos durante a sua permanência na universidade. 